\title{
Contributions to particle fluxes and proxies in marine geosystems
}

In this volume we present a couple of selected publications focussing on modern aspects of particle fluxes and proxies within marine geosystems. Over the last few decades, geoscientists have studied the processes and products in marine environments down to the smallest detail for a better understanding of marine geosystems. These multidisciplinary approaches have led to a novel understanding of our planet as a whole. One potential reason for this better understanding is the study of particle fluxes and the evaluation of proxy data, a major objective being the reconstruction of ancient environmental conditions and their regional and global changes within a suitable time frame.

The study of particle fluxes and proxies is aimed at the detailed investigation of pathways of material and energy into the oceanic system, the organic and inorganic particle production within the near surface water masses, and their final settling within the marine sediments. The major aspect, however, concerns the entire vertical and lateral migrations within the water column influencing any particle brought into the ocean or directly produced within the oceanic realm, as well as any diagenetic alteration in near surface sediments.

On the basis of re-estimates, the first paper by Schlünz and Schneider discusses the modern global fluvial organic-carbon discharge into the oceans and the burial rates that represent an important factor in the global carbon cycle. The next paper by Gerhardt et al. presents the important aspect of how living biota are recorded as fossils within marine sediments and how much of their information potential is lost due to early dissolution and diagenetic alteration. The following couple of papers discuss these diagenetic changes from a more geochemical point of view. Haese et al. present a comparative study of the diagenetic behaviour of iron and manganese from surface sediments within a continental slope setting. The application of Moesbauer spectroscopy allowed them to demonstrate that the behaviour of various iron and manganese ions plays an important role during diagenesis on the one hand, but always remaining difficult to differentiate, on the other. The article by Däumler discusses the important aspect of diagenetic dissolution of biogenic magnetite produced by bacteria in surface sediments, thus leading to a better understanding of how bacterial magnetite is recorded, which in turn yields information about the earth's changing magnetisation. These geochemical and geophysical aspects and the quantification of processes provide data sets for modelling and the respective approaches are presented in the paper by Adler et al. who have studied the sulphate reduction in marine sediments by means of computer simulations. The past few years have also witnessed another important aspect of particle and fluid fluxes unravelled by the discovery of tectonic dewatering and the input of fluids from the lithosphere. The paper by Zühlsdorff et al. focuses on fluid-transport regimes from the lithosphere to plateboundary processes in correlation with bottom simulating reflectors as indicators of gas hydrates.

The following set of three papers concentrates on a special group of marine pelagic biota as a proxy indicator for changing current regimes and water masses. The paper by Karwath et al. describes the spatial distribution of a characteristic phytoplankton species within the water column of the tropic equatorial Atlantic, while Esper et al. use this approach for the reconstruction of paleoceanographic conditions during the global change from glacial to interglacial conditions. In a similar way, this biotic proxy method is applied in the paper by Hildebrand-Habel and Willems to reconstruct environmental conditions during earth history from Maastrichtian to early Miocene times. The paper clearly demonstrates how the study and investigation of our modern world provides the key to the understanding of the past and that this ancient geological time is so much different from our present-day conditions that we have to imagine the following picture: our modern Holocene time seems to represent an extreme situation during earth history rather than being the normal condition. This is also 
documented in the paper by Scheibner et al. with its special focus on ancient slope to basin sediment transects.

The last three papers focus on the Holocene itself. The study of large coral colonies as prominent recorders of sea-surface temperature variability and climate change has gained increasing importance over the last decade. The paper by Kuhnert et al. describes the potential of monitoring climate variability in the skeleton of reef corals with the time resolution of one month for the last 116 years. In a similar way, the paper by Draschba et al. presents a study of climate variability recorded in proxy data and the skeletal density of Scleractinian corals since 1350 AD. Finally, Moustafa et al. apply this method to explain climate variability in the same resolution for selected time windows within the mid-Holocene.

Although this collection of papers is very selective, it demonstrates how various geoscientific disciplines co-operate to interpret earth history and aspects of global change for the evaluation of present-day conditions and, furthermore, to improve the quality of predictions. All these studies were carried out within the frame of the Graduiertenkolleg "Particle Fluxes in Marine Geosystems" (co-ordinated by H. Willems) in the Department of Geosciences at Bremen University,

in many cases in co-operation with national and international partners. After a funding period of 10 years, this multidisciplinary project will come to a close in September 2000. We would like to express our gratitude to the Deutsche Forschungsgemeinschaft and the State of Bremen for financial support of the project as well as to Bremen University for the highly esteemed co-operation. Further thanks are due to Christine Höll and Frank Lamy for their support in the organization of this volume and to the numerous reviewers for their skilled work. The papers benefited from reviews by:

E. Appel, K. Bandel, T. Bechstädt, E.T. Channell, T. Correge, G. Einsele, P. Grathwohl, J. Grötsch, C. Hemleben, R.D. Hyndmann, H. Keupp, N. Kukowski, A.J. le Clerc, J. Matthiesen, J. Mutterlose, S. Pfeiffer, M. Schlüter, P. Swart, K. Stattegger, R. Stein, A. de Vernal, G. Versteegh, K. Wallmann, J. Young,

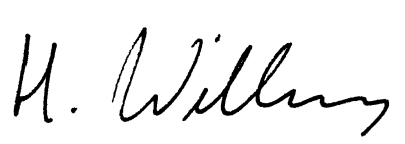

Helmut Willems

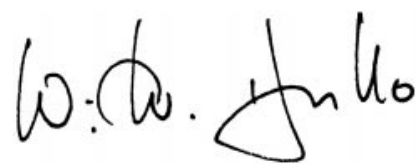

Wolf-Christian Dullo 